\title{
Enhanced material models for the process design of the temperature dependent forming behavior of metastable steels
}

\section{Journal Article}

Author(s):

Krauer, Jürg; Hora, Pavel

Publication date:

2012-12

Permanent link:

https://doi.org/10.3929/ethz-b-000038466

Rights / license:

In Copyright - Non-Commercial Use Permitted

Originally published in:

International Journal of Material Forming 5(4), https://doi.org/10.1007/s12289-011-1057-4 


\title{
Enhanced material models for the process design of the temperature dependent forming behavior of metastable steels
}

\author{
Jürg Krauer • Pavel Hora
}

Received: 27 April 2010 / Accepted: 18 June 2011 / Published online: 11 August 2011

(C) Springer-Verlag France 2011

\begin{abstract}
In this paper, the main parameters for the process design of thermo active deep drawing processes with metastable steels are specified. As a consequence of the strain- and temperature-dependent martensitic phase transformation, the CrNi-steels have a very complex forming and failure behavior. Particularly, the strong heating of the blank, induced by the hardening increase, influences the yield properties, the failure and the tribological system. Hence, a robust process design with FEM is subordinated to the correct virtual description of these process parameters. Both, experimental methods for an accurate measurement of the forming, friction and failure properties, as well as numerical models were introduced in this study. Using these models, temperature dependent parameters like phase transformation from $\gamma$-austenite to $\alpha^{\prime}$-martensite, yield properties, failure or friction can be easily included into the virtual process modeling. The model was successfully validated by biaxial stretching tests and rectangular cups, drawn at different tool temperatures.
\end{abstract}

Keywords Deep drawing · Stainless steel - AISI304 - Phase transformation $\cdot$ eMMFC $\cdot$ FLCT $\cdot$ Temperature dependent friction

\section{Introduction}

Austenitic stainless steels, such as AISI304, have a big potential in forming applications. For example in architec-

J. Krauer $(\bowtie) \cdot$ P. Hora

Institute of Virtual Manufacturing, ETH Zurich,

Tannenstrasse 3,

8092 Zurich, Switzerland

e-mail: juerg.krauer@alumni.ethz.ch

URL: www.ivp.ethz.ch ture, food industry or automotive industry, austenitic stainless steels are used because of the corrosion and heat resistance or decorative qualities. The metastable forming behavior of these kinds of steels is a big challenge for the production and as a consequence also for the numerical simulations.

As a result of the significant plastic work, induced by the hardening increase of the deformed material, the process temperature during cold forming processes, starting at room temperature, raises up to about $90^{\circ} \mathrm{C}$ locally. On the one side, this temperature increase leads to a smaller amount of martensite in the drawing-in area between die and binder, which is a positive aspect for the forming behavior. On the other side, the reduced amount of martensite in the punch area leads to a decreasing transmittable drawing force. In addition, the heating has a strong influence on the lubrication regime. Dependent on such mechanisms the process shows a strong temperature sensitivity.

Today, the producing industry takes advantage of the positive respectively negative aspects of this temperature increase by temperature controlled tools. Heating the die and the binder and cooling the punch leads to an optimal deep drawing behavior. Therefore, a process model for thermo active deep drawing processes with metastable stainless steels is needed. As described in [1], this process model needs to consider solutions for phase transformation, yield properties, failure and friction, which take into account the particular thermal behavior.

For the characterization of the phase transformation ( $\gamma$-austenite to $\alpha^{\prime}$-martensite), the Hänsel model was used. The nonisothermal Hänsel model is an incremental description of the martensite formation in dependency of temperature, deformation and forming history. The martensite formation rate is physically defined as a function of 
Table 1 Mechanical properties of the AISI304

\begin{tabular}{llllll}
\hline $\mathrm{Rp}_{0.2}\left[\mathrm{~N} / \mathrm{mm}^{2}\right]$ & $\mathrm{Rm}\left[\mathrm{N} / \mathrm{mm}^{2}\right]$ & $\mathrm{A}_{\mathrm{g}}[\%]$ & $\mathrm{R}_{0}[-]$ & $\mathrm{R}_{45}[-]$ & $\mathrm{R}_{90}[-]$ \\
\hline 287 & 653 & 44.6 & 0.80 & 1.35 & 0.85 \\
\hline
\end{tabular}

temperature and actual martensite content. With a new process set-up for the evaluation of the model parameters, an accurate determination of the martensite formation and total hardening is possible. The more accurate and material specific approach of the Hänsel parameters is one of the important contribution for a better applicability of the Hänsel constitutive model.

For the numerical failure prediction of metastable steels, the enhanced modified maximum force criterion (eMMFC) needs to be extended by the temperature and the actual martensite content. The experimental data of standard tensile tests allow to determinate a temperature dependent forming limit curve (FLCT). For a continuous temperature dependent failure criterion, a surface can be laid over the non isothermal curves allowing interpolations for nonuniform temperature regimes.

Because of the heating during the process, the tribological system changes significantly and the use of a constant friction model, like Amontons law or the shear friction model, is no longer accurate enough. This effect is pointed out by heated strip drawing tests. The consideration of temperature is essential for capturing the friction phenomena in industrial deep drawing processes using stainless steels.

\section{Materials}

Metastable austenitic stainless steel AISI304

The material used in this study is a metastable austenitic steel (AISI304) with a thickness of $0.72 \mathrm{~mm}$. The chemical analysis of the steel showed a Cr-content of $18.0 \%$ and a Ni-content of $8.9 \%$. The mechanical properties are listed in Table 1 .

\section{Martensite formation}

With the start of a plastic deformation, a large number of dislocations are typically built. With the increase of the deformation, the dislocations were concentrated in shear bands. The shear bands can be made up of an accumulation of voids, twins or $\varepsilon$-martensite. In those shear bands, the $\gamma-\varepsilon$-transformation is taking place. Martensite is existent in different characteristics. In alloyed steels we have to distinguish between $\varepsilon$ martensite with hexagonal and $\alpha^{\prime}$-martensite with cubic body centered lattice. The first $\alpha^{\prime}$-martensite-areas, which are typically built in the $\varepsilon$-zones, appear already by a marginal increase of the deformation. $\alpha^{\prime}$-martensite can also be built directly from the austenite.
Hardening behavior

The formed strain induced martensite in metastable austenitic steels has an important influence on the mechanical properties such as ductility, strength and hardness of forming parts.

According to the formation conditions, the geometrical structure of the strain induced martensite areas can look differently (e.g. needles or plates).

The hardening behavior is dependent on the formability and the temperature (see Fig. 1).

Therefore, the total hardening is:

$k_{f}^{t o t}=k_{f}^{\gamma}+\Delta k_{f}^{\gamma \rightarrow \alpha^{\prime}} \cdot V_{M}$

$k_{f}^{\text {tot }}$ is the total hardening, $k_{f}^{\gamma}$ the austenite hardening, $\Delta k_{f}^{\gamma \rightarrow \alpha^{\prime}}$ the hardening increase because of the phase transformation from $\gamma$-austenite to $\alpha^{\prime}$-martensite and $V_{M}$ the actual martensite content.

\section{Experimental procedure}

\section{Evaluation of the hardening}

Standard tensile tests at room temperature lead to a martensite amount of about 10 to $15 \%$ by volume in the specimen for the AISI304-material. For a reasonable fitting of an appropriate theoretical model, a higher amount of martensite is desired.

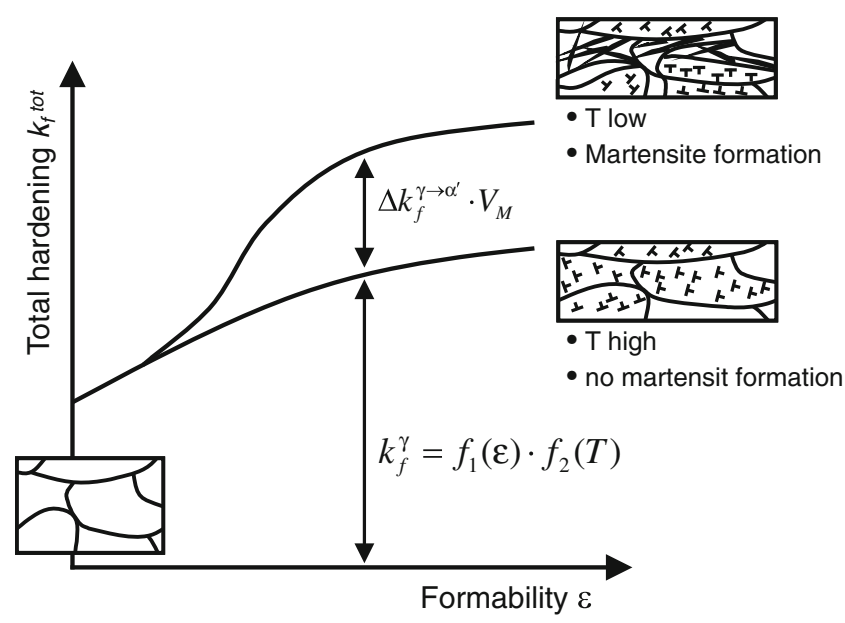

Fig. 1 Hardening behavior of a AISI304-steel 
Fig. 2 Hemispherical heatable punch with the position of the six heating elements
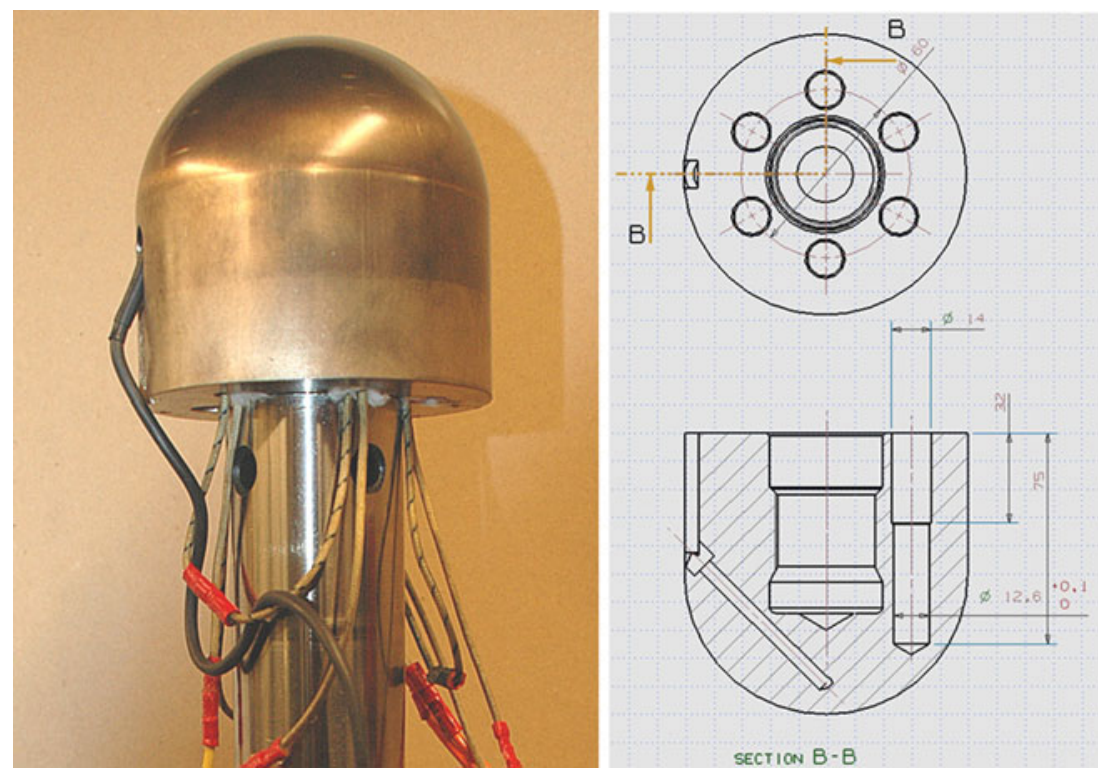

For this study, the tensile tests were done in a climatic chamber at temperatures from $0^{\circ} \mathrm{C}$ to $80^{\circ} \mathrm{C}$. The martensite content is measured with a magneto inductive measuring method. This method allows identifying the content of the ferromagnetic phase in the material. For the test series a Fischerscope MMS (Fischer) is used, which allows continuous measuring.

\section{Temperature dependent FLC}

For the determination of the temperature influence on the Forming Limit Curves, Nakajima tests [2] were done at different temperatures. With a heatable hemispherical punch it was possible to adjust a homogeneous temperature distribution. The deformation was monitored with the optical measurement system ViALUX. Each single test was done three times for reproducibility reasons.

For the adjustment of the different temperatures, a heatable hemispherical punch was used. Figure 2 shows a drawing of the punch. The use of 6 identical heating elements, circularly arranged, gives a very homogeneous temperature distribution. A thermal sensor $5 \mathrm{~mm}$ below the pole of the punch allows controlling the temperature. With this punch, it is possible to conduct Nakajima tests at temperatures from room temperature (RT) up to $150^{\circ} \mathrm{C}$. In this case, tests were done at RT $\left(\approx 22^{\circ} \mathrm{C}\right), 40,60,80$ and $100^{\circ} \mathrm{C}$.

According to the new ISO norm for the determination of forming limit curves in laboratory [3], Nakajima test specimens with a parallel shaft (widths: 20, 50, 80, 90, $100,120 \mathrm{~mm}$ ) were taken.

\section{Temperature dependent friction coefficient}

The friction coefficient was experimentally determined on a strip drawing test machine. With a newly developed heatable drawing die, the experimental setup allows to run experiments at elevated temperatures. In this case, experiments were done at room temperature, $50^{\circ} \mathrm{C}$ and $80^{\circ} \mathrm{C}$.
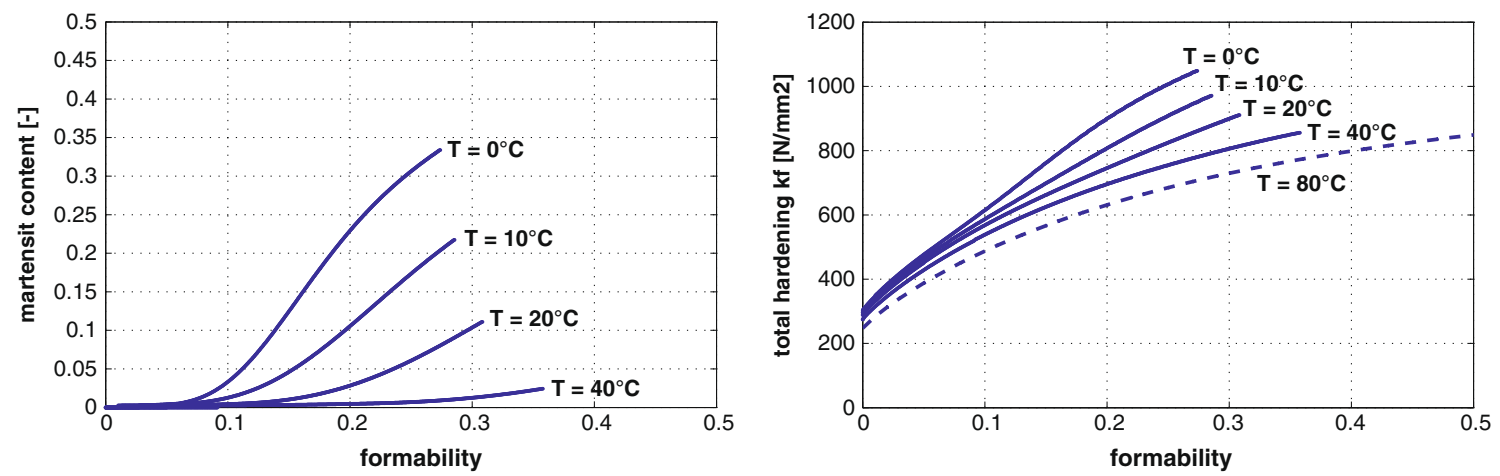

Fig. 3 Evolution of the martensite content (left) and yield curves (right) for different experimental temperatures 


\section{Experimental results}

\section{Hardening behavior}

The results of the tensile tests in the climatic chamber show the temperature dependent phase transformation from austenite to $\alpha^{\prime}$-martensite very clearly. For low temperatures of $0-10^{\circ} \mathrm{C}, 30-35 \%$ martensite volume is reached, on the other hand, for high temperatures, the phase transformation is negligible (Fig. 3, left). As a consequence of the phase transformation, it can be observed, that the yield stress rises with increasing martensite content for lower temperatures (Fig. 3, right).

\section{Temperature dependent FLC}

Figure 4 shows the achieved fracture heights for the different Nakajima geometries and the different punch temperatures. It is obvious, that the experiments with higher temperature fail at an earlier process time. This tendency can be observed for all geometries, but is not that distinct for more biaxial formed specimens.

The evaluation of the FLC was done with Matlab. The used Matlab-code is based on a method which was first proposed by Volk at the FLC Zurich'06 [4, 5]. In this time-continuous evaluation method, the beginning of the localized necking is determined using the similarity between the regular grid for the optical measurement and the typical mesh of a finite element simulation. On this account, the typical FE approaches and calculation methods can be used.

The beginning of the localized necking has effects on the strain rate. The instability leads to higher strain rates in the instability zone - and as consequence to a decrease of the strain rate outside [4-6].

The resulting forming limit curves for the different temperatures are depicted in Fig. 5. The diagram shows the decreasing forming limit with increasing temperature very clearly. For the specimens with a $50 \mathrm{~mm}$ shaft, the major

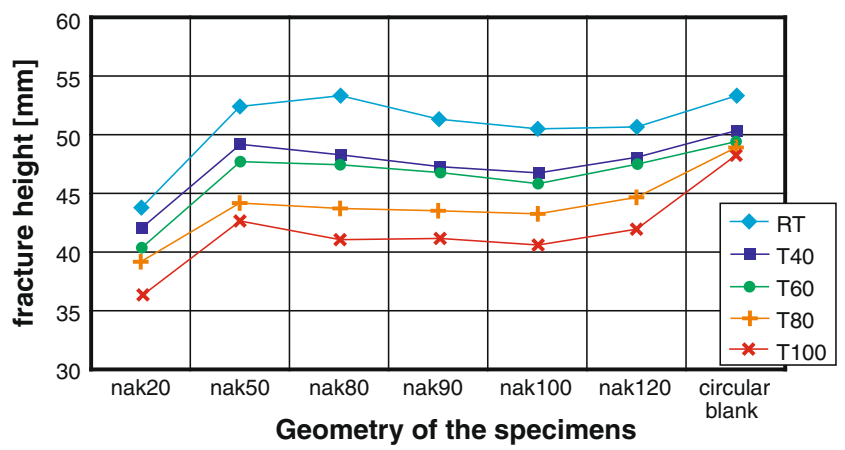

Fig. 4 Achieved fracture heights for the different specimen geometries and temperatures

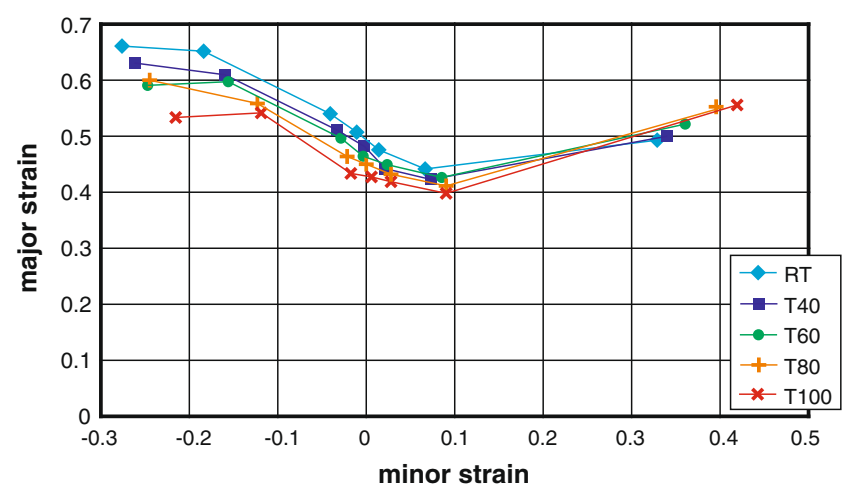

Fig. 5 Forming Limit Curves for the analyzed temperatures

strain at room temperature is almost $20 \%$ higher than for the same specimen at $100^{\circ} \mathrm{C}$, at the plain-strain state about $10 \%$.

Temperature dependent friction coefficient

Figure 6 shows the results of the strip drawing tests. Experimental tests were done at three different velocities $(0.05,0.1,0.5 \mathrm{~m} / \mathrm{s})$, two different testing temperatures $\left(23^{\circ} \mathrm{C}\right.$, $60^{\circ} \mathrm{C}$ ) and with or without drawing foil. As lubricant, Raziol CLF260 was used. The prestrain of the specimen was $20 \%$. The results show very clear, that the friction coefficient is higher for all conditions at elevated temperatures. Using a drawing foil reduces the influence of the temperature.

\section{Theoretical models}

Nonisothermal material model for the martensite content

The nonisothermal Hänsel [7] model is based on the Tsuta and the Olson-Cohen model [8-10]. The martensite formation rate is physically defined as a function of the

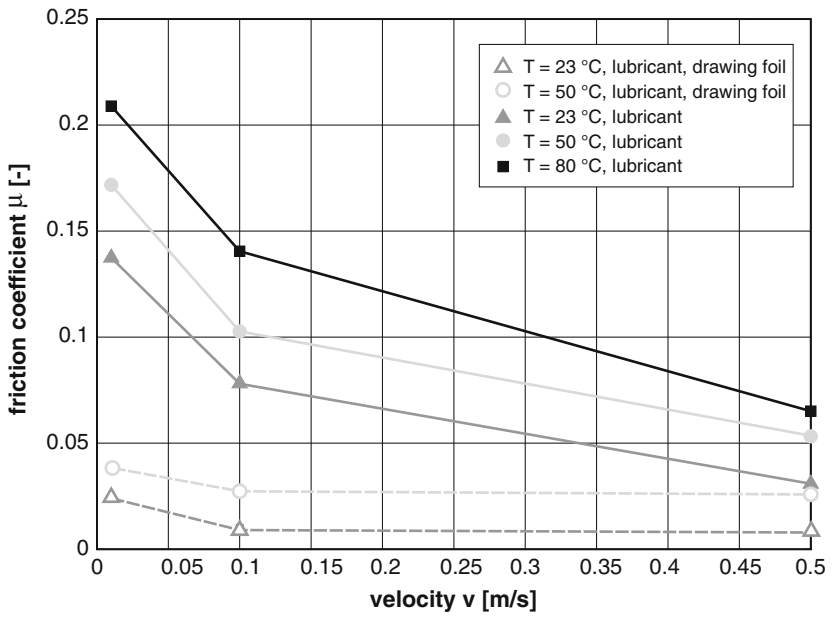

Fig. 6 Experimental friction coefficient for room temperature $\left(23^{\circ} \mathrm{C}\right)$ and elevated temperatures $\left(\mathrm{T}=50^{\circ} \mathrm{C}, \mathrm{T}=80^{\circ} \mathrm{C}\right.$. 
Table 2 Hänsel parameters of the AISI304. Left: martensite deformation rate, Eq. 2; Right: hardening, Hockett-Sherby approach, Eqs. 3, 4 and 5

\begin{tabular}{llllllll}
\hline $\mathrm{A}$ & $\mathrm{B}$ & $\mathrm{C}$ & $\mathrm{D}$ & $\mathrm{A}_{\mathrm{HS}}$ & $\mathrm{B}_{\mathrm{HS}}$ & $\mathrm{m}$ & $\mathrm{n}$ \\
\hline 111.02 & 0.1937 & -73.89 & 0.1440 & 247.25 & 991.15 & 3.08 & 0.8979 \\
$\mathrm{p}$ & $\mathrm{Q}$ & $\varepsilon_{0}$ & $\mathrm{~V}_{\mathrm{M} 0}$ & $\mathrm{~K}$ & $\Delta \mathrm{k}_{\mathrm{f}}$ & & \\
7.212 & 2782 & $0.01+T \cdot 0.002$ & 0.0026 & 0.0028 & 527.86 & & \\
\hline
\end{tabular}

temperature and the actual martensite content. The martensite formation rate according to Hänsel is

$\frac{d V_{M}}{d \varepsilon}=\frac{B}{A} \cdot e^{\frac{Q}{T}} \cdot\left(\frac{1-V_{M}}{V_{M}}\right)^{\frac{1+B}{B}} \cdot V_{M}^{p} \cdot[0.5 \cdot(1-\tanh (C+D \cdot T))]$

where $A, B, C, D, p, Q$ are the Hänsel parameters which have to be determined with experiments, $V_{M}$ is the martensite volume fraction and $T$ is the temperature. $V_{M O}$ and $\varepsilon_{0}$ are the parameters representing the start of approximation, which should be taken temperature dependent. For better extrapolation results, an additional measuring point from a biaxial stretch drawing test is taken into account $\left(V_{M}=0.266, T=27.1^{\circ} \mathrm{C}, \varepsilon=0.59\right)$.

Hänsel integrated the martensite formation model into a hardening model for steels with phase transformation using the Hockett-Sherby approach:

$k_{f}^{g e s}=f_{1}(\varepsilon) \cdot f_{2}(T)+\Delta k_{f}^{\gamma \rightarrow \alpha^{\prime}} \cdot V_{M}$

with

$f_{1}(\varepsilon)=\left[B_{H S}-\left(B_{H S}-A_{H S}\right) \cdot \exp \left(-m \cdot \varepsilon^{n}\right)\right]$

and

$f_{2}(T)=[1-K \cdot(T-293)]$

$B_{H S}, A_{H S}, m$ and $n$ are the Hockett-Sherby-Parameters; $\Delta k_{f}^{\gamma \rightarrow \alpha^{\prime}}$ the hardening difference between austenite and martensite; $f_{2}(T)$ a temperature function with a constant $K$.
The approximation of the hardening model was made in three steps:

1. Determination of the yield stress $\rightarrow A_{H S}$

2. Austenite yield curve (353 K-tensile test) with constraint $\frac{\partial k_{f}}{\partial \varepsilon}=k_{f} \rightarrow B_{H S}, m, n$

3. Fitting of the parameters $K$ and $\Delta k_{f}^{\gamma \rightarrow \alpha^{\prime}}$ using all tests $\rightarrow K, \Delta k_{f}^{\gamma \rightarrow \alpha^{\prime}}$

The resulting parameters for the material used are listed in Table 2. The comparison of the experimental and the calculated data for martensite content and yield stress shows a very good correlation (Fig. 7).

Virtual failure prediction

For the numerical prediction of the Forming Limit Curve, the enhanced modified maximum force criterion (eMMFC) according to Hora and Tong [11, 12] was chosen. The delivered results agree very well with the experimentally determined forming limit curves [13].

The idea behind the MMFC-Model [14, 15] is to account for an additional increase in hardening, which is triggered by the deviation from the initial, homogeneous stress condition - e.g. uniaxial tension - to the stress condition of local necking and with this to the point of plane strain.

An extension of the MMFC was proposed by Hora et al. $[11,12]$, in which an additional term introduces the influence of sheet thickness $t$ and also accounts for material crack propagation. The extended equation is formulated as
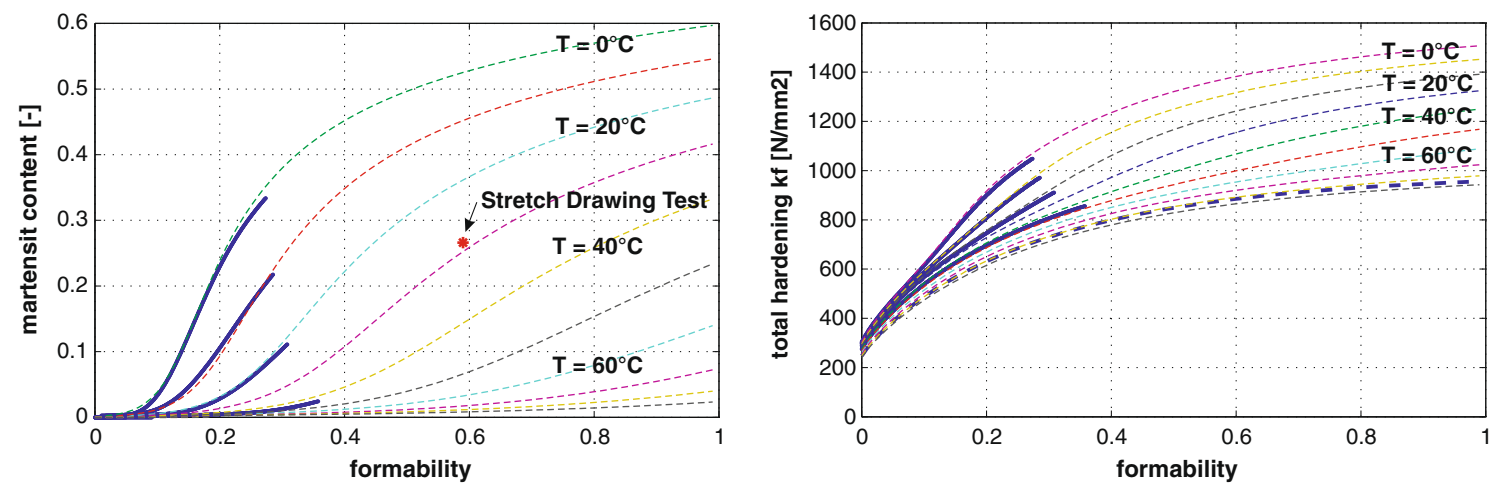

Fig. 7 Approximation and extrapolation of the experimental data with the Hänsel-model (Temperatures: From $0^{\circ} \mathrm{C}$ to $100^{\circ} \mathrm{C}$ ). Left: martensite content; Right: yield stress 
Fig. 8 Numerical evaluation method for the FLCT $\left(c_{p}\right.$ : heat capacity, $h$ : hardening, $T$ : temperature, $V_{M}$ : martensite content, $w_{p l}$ : plastic work, $\beta$ : strain ratio, $\varepsilon_{\text {eq }}$ : equivalent strain, $\rho$ : density, $\kappa$ : heat transfer coefficient)

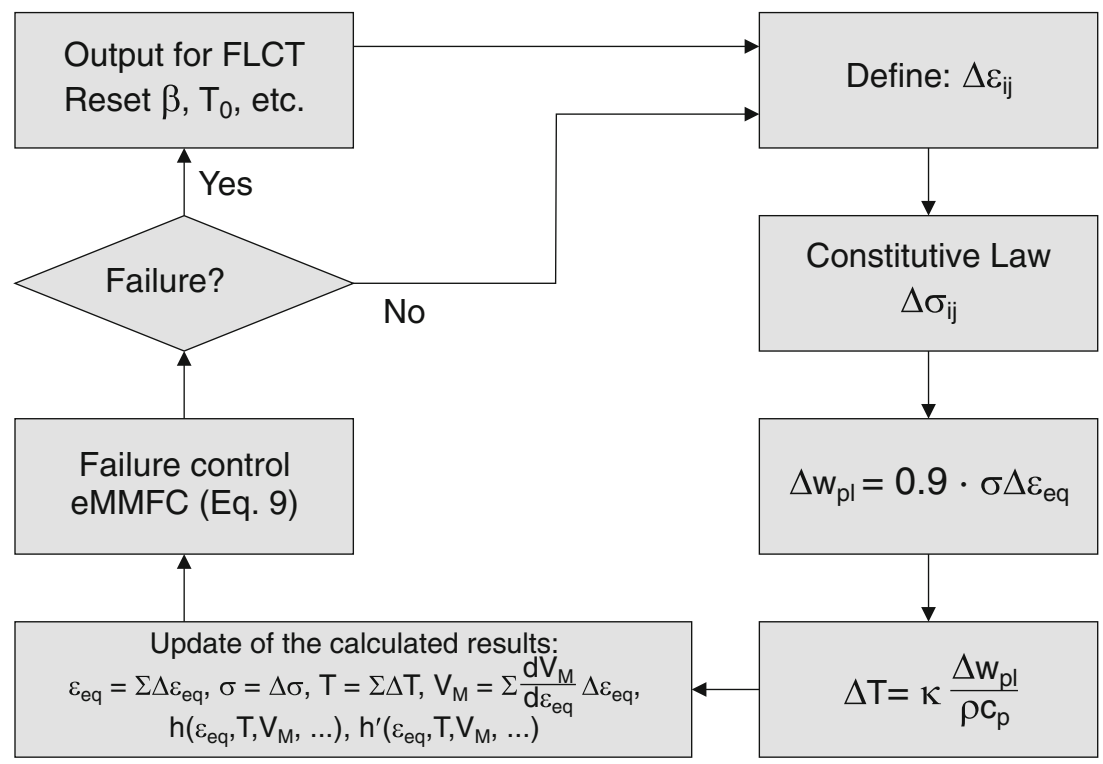

$\frac{\partial \sigma_{11}}{\partial \varepsilon_{11}}\left[1+\frac{t}{2 r}+e(E, t)\right]+\frac{\partial \sigma_{11}}{\partial \beta} \frac{\partial \beta}{\partial \varepsilon_{11}} \geq \sigma_{11}$

with

$e(E, t)=E_{0}\left(\frac{t}{t_{0}}\right)^{p}$

$E_{0}$ is a material constant, exponent $p$ is influenced by the thickness $t, r$ is the sheet curvature radius and $\beta$ is the strain ratio.

In case of metastable austenitic CrNi-steels, $E_{0}=0.1$ for the material constant $\mathrm{E}_{0}$, and $p=0.6$ for the exponent $\mathrm{p}$ has been evaluated as appropriate.

The consideration of the influence of the temperature $T$ and the actual martensite content $V_{M}$ on the failure is essential especially for metastable steels. In this case, $\sigma_{11}$ is a function of

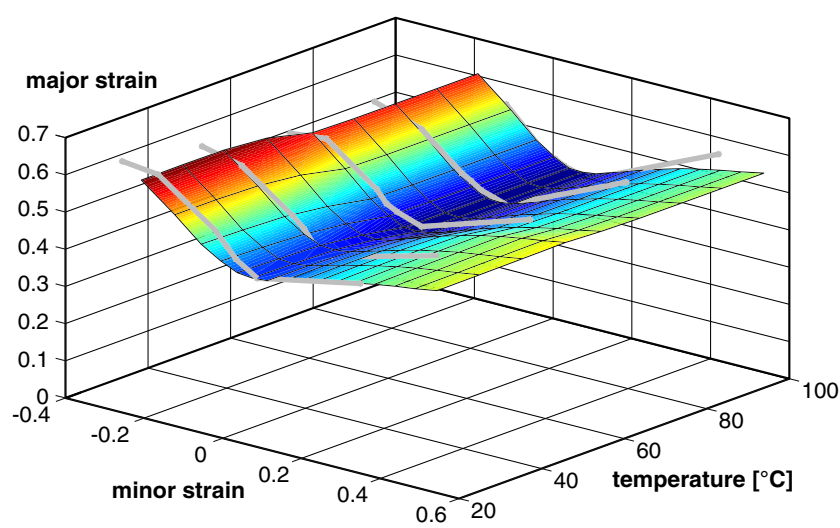

Fig. 9 Comparison of the experimental forming limit curves and the calculated forming limit surface (curves: experimental results with data points, surface: eMMFC, calculated FLCT) $\sigma_{11}=f\left(\varepsilon_{11}, \beta, T, V_{M}\right)$

and Eq. 6 extends to

$\frac{\partial \sigma_{11}}{\partial \varepsilon_{11}}\left[1+\frac{t}{2 r}+e(E, t)\right]+\frac{\partial \sigma_{11}}{\partial \beta} \frac{\partial \beta}{\partial \varepsilon_{11}}+\frac{\partial \sigma_{11}}{\partial T} \frac{\partial T}{\partial \varepsilon_{11}}+\frac{\partial \sigma_{11}}{\partial V_{M}} \frac{\partial V_{M}}{\partial \varepsilon_{11}} \geq \sigma_{11}$

The advantage of the eMMFC can be found in its independence of an inhomogeneity assumption.

The form of the yield locus directly enters the model trough the additional term. For materials with flattened, non-quadratic yield loci, local necking will quickly follow after diffuse necking. On the other hand, materials with a Hill'48-type and high R-values will show a much extended diffuse necking with delayed local necking.

Due to its differential form, the eMMFC can be implemented incrementally. This allows the computation of non-linear strain paths and also a direct evaluation of the FLC during incremental FEM simulation [15].

The experimental data allows to determinate a temperature dependent FLC. The numerical evaluation method for the FLCT is shown in Fig. 8. With the description of the hardening of the eMMFC (Eq. 10, see $[14,15])$ a forming limit surface (FLS) can be evaluated under the assumption of linear strain paths. With a variation of the heat transfer coefficient $\kappa$ from 0 (quasistatic state) to 1 (adiabatic state) and the determination of

Table 3 Parameters for the friction model

\begin{tabular}{lllllll}
\hline $\mathrm{a}$ & $\mathrm{b}$ & $\mathrm{c}$ & $\mathrm{f}$ & $\mathrm{k}_{1}$ & $\mathrm{k}_{2}$ & $\mathrm{k}_{3}$ \\
\hline $1.7 \mathrm{e}-10$ & 36185 & 1339.7 & 0.2859 & -2.0742 & 2.3045 & 0.0891 \\
\hline
\end{tabular}




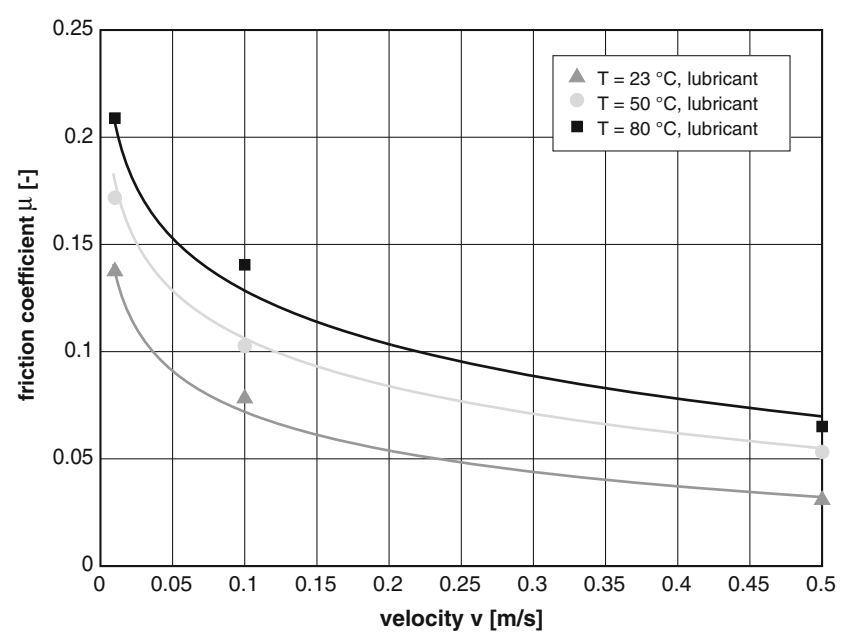

Fig. 10 Approximation of the heated strip drawing tests with the model of Grüebler (Eq. 13)

the failure point for different $\beta$, the FLCT can be calculated. Because of the slightly biaxial forming behavior at the beginning of the deformation, a small biaxial pre-strain was considered. For a continuous temperature dependent failure criterion, a surface can be laid over the nonisothermal failure curves (Fig. 9) [16, 17].

$k_{f}^{\prime} \leq \frac{\left(f(\alpha)+\frac{f^{\prime}(\alpha) g(\beta) \beta}{\beta^{\prime}(\alpha) \varepsilon_{v}}\right)}{f(\alpha) g(\beta)} \cdot k_{f}$

Temperature dependent friction model

According to Vogel [18], the temperature dependency of the viscosity $\eta$ can be expressed with

$\eta=A e^{\frac{B}{T+C}}$

where $T$ is the temperature in Kelvin and $A, B$ and $C$ are constants. The temperature dependency of the friction coefficient $\mu$ can be expressed in a similar way

$\mu=1-a e^{\frac{b}{T+c}}$
Fig. 11 Parts for the validation of the process model (left: biaxial stretch drawing part, right: rectangular cup). The dots are the measuring points
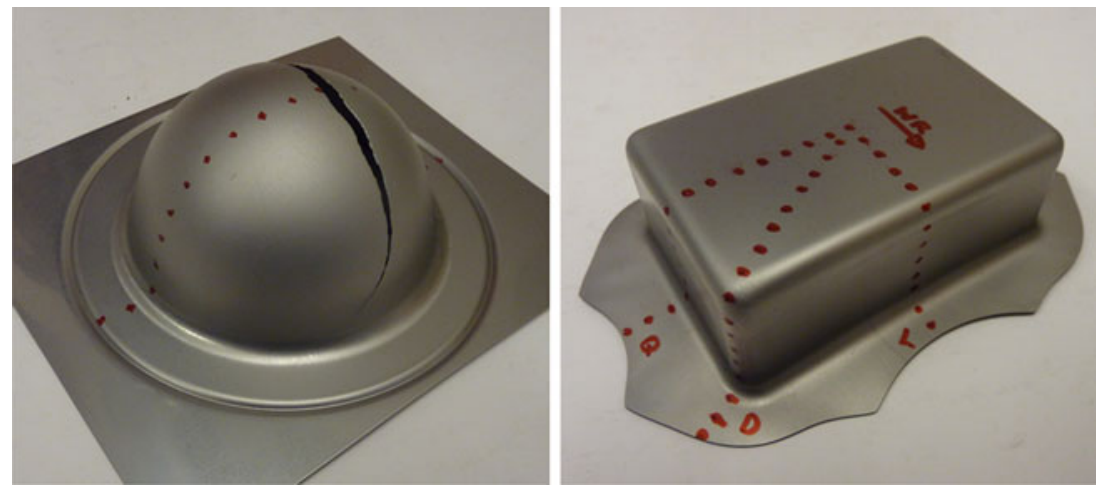

Fig. 12 Comparison of the experimental and calculated punch force for different punch temperatures (Exp: Experiment, SF: FE-Simulation with StreckForm)

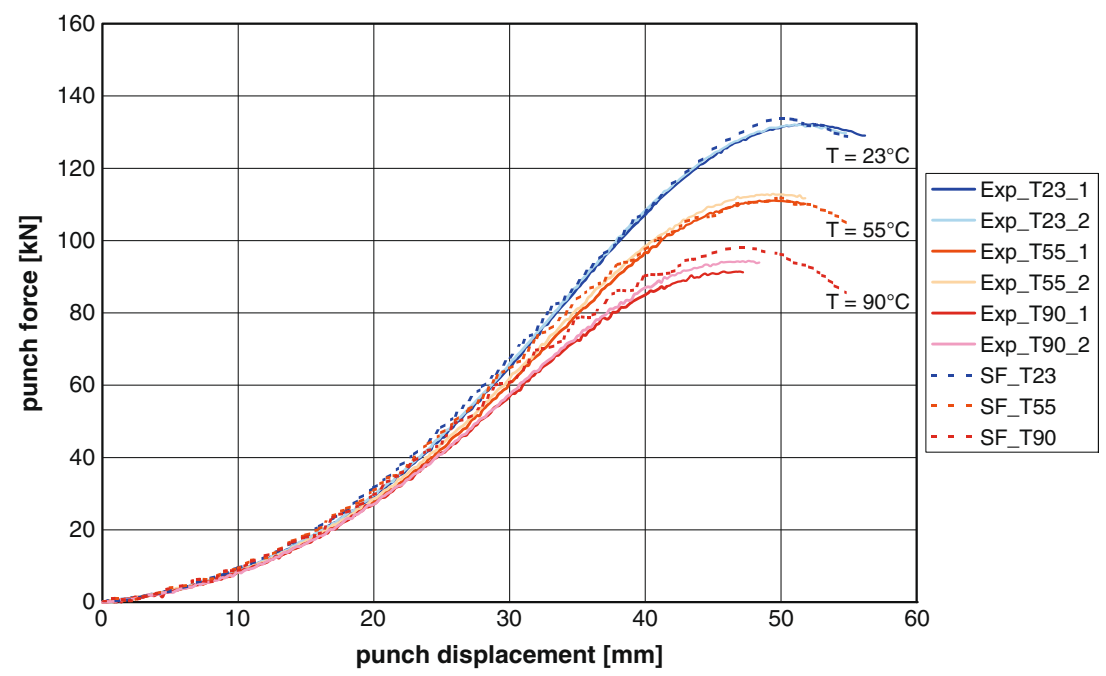


Fig. 13 Comparison of the experimental and calculated martensite fraction for different punch temperatures (after cracking, Exp: Experiment, SF: FE-Simulation with StreckForm)

Fig. 14 Comparison of the experimental and calculated punch force for different tool temperatures (Exp: Experiment, SF: FE-Simulation with StreckForm)

Fig. 15 Comparison of the experimental and calculated martensite fraction for different tool temperatures (sections L, $\mathrm{D}$ and $\mathrm{Q}$ as illustrated in Fig. 13, Exp: Experiment, SF: FESimulation with StreckForm)
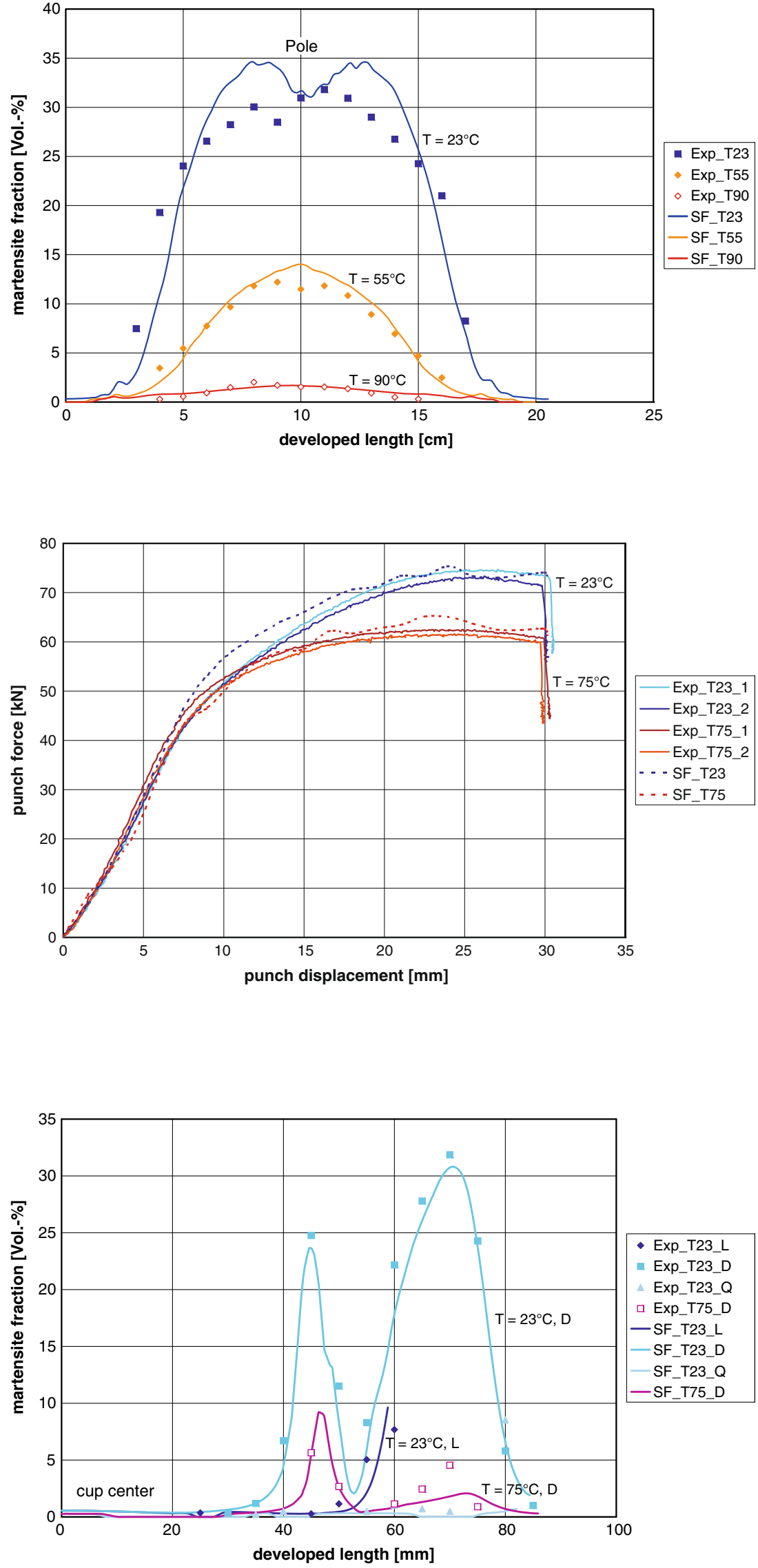
In general, the friction in sheet metal forming of stainless steels takes place in the mixed lubrication regime. For a physically correct model, a combination of the boundary friction and the hydrodynamic friction regime needs to be taken and the real contact area has to be known. But in the macroscopic finite element simulation, the determination of the real contact area is not possible, because the surface geometry with the asperities is not considered. Therefore, Grüebler [19] proposes a model, which combines the velocity and temperature dependency of the friction coefficient $\mu$

$\mu=f \cdot\left(k_{1} \cdot v_{r e l}^{k_{3}}+k_{2}\right)\left(1-a \cdot v_{r e l}^{k_{3}} \cdot e^{\frac{b}{T+c}}\right)$

$v_{\text {rel }}$ is the relative velocity, $T$ the temperature, $k_{1}, k_{2}, k_{3}, a, b, c$ and $f$ are constants. This model is a macroscopic friction description. Hence, it is not possible to distinguish between boundary and hydrodynamic friction. The model needs to be calibrated with strip drawing tests.

With the parameters in Table 3, the experimental strip drawing tests at different temperatures (Fig. 6) can be approximated very well with this model (Fig. 10).

\section{Validation}

The validation of the described process model was made with two different parts (Fig. 11). On the one side, biaxial stretch drawing parts at different punch temperatures $\left(23^{\circ} \mathrm{C}\right.$, $55^{\circ} \mathrm{C}$ and $90^{\circ} \mathrm{C}$ ) were made, on the other side, rectangular cups at different tool temperatures $\left(23^{\circ} \mathrm{C}\right.$ and $\left.75^{\circ} \mathrm{C}\right)$ have been deep drawn. The comparison of the simulated drawing force as well as the resulting martensite fraction shows a good accordance with the experimental measurements. The simulations were done with the FE-code StreckForm. The specific process and simulation parameters are listed in [20].

Figures 12, 13 and 14 show the comparison of the experimental and calculated punch forces for both cases, the stretch drawing and the rectangular deep drawing part. It is obvious that the accordance is quite good and the model reflects the effects of the different tool temperatures in an accurate way.

In Figs. 13 and 15, the resulting martensite fraction is pictured. The comparison of the different values for each punch, respectively tool temperature illustrates the high temperature dependency of the phase transformation from austenite to martensite. The figure shows, that the martensit fraction can be very well predicted by the FE-simulation.

\section{Conclusions}

In this paper, theoretical approaches for the description of the influence of temperature on the hardening behavior, the failure and the tribological system for austenitic stainless steels, which was showed by different experimental tests, are introduced. With an enhanced Hänsel model for the hardening, the eMMFC for the calculation of the temperature dependent forming limit curves and Grüeblers equation for the temperature and velocity dependent friction coefficient, we have approved theoretical models for a correct description of the thermoactive process behavior of metastable steels. The accuracy of the process model could be successfully demonstrated with the comparison of experimental and calculated results of real deep drawing parts.

Acknowledgements The authors are very grateful to CTI, the Innovation Promotion Agency of Switzerland, for financial support of this study.

\section{References}

1. Krauer J, Hora P (2009) Thermoactive process modelling of deep drawing with austenitic stainless steels. Proceedings of the IDDRG'09, pp 17-28

2. Nakazima K, Kikuma T, Hasuka K (1968) Study on the formability of steel sheets. Yawata Technical Report No. 264, pp $141-154$

3. ISO/DIS 12004-2 (2006) Metallic materials - Sheet and strip Determination of forming limit curves - Part 2: Determination of forming limit curves in laboratory

4. Volk W (2006) New experimental and numerical approach in the evaluation of the FLD with the FE-method. Proceedings of the FLC Zurich, pp 26-30

5. Eberle B, Volk W, Hora P (2008) Automatic approach in the evaluation of the FLD-curve. Proceedings of the Numisheet'08, pp 279-284

6. Hora P, Eberle B, Volk W (2009) Numerical methods for a robust user-independent evaluation of Nakajima tests for the FLC determination. Proceedings of the IDDRG'09, pp 437-448

7. Hänsel A (1998) Nichtisothermes Werkstoffmodell für die FESimulation von Blechumform-prozessen mit metastabilen austenitischen CrNi-Stählen, PhD-Thesis ETH Nr. 12672, Fortschr.-Ber. VDI Reihe 2 Nr. 491, VDI Verlag

8. Ramirez JAC, Tsuta T, Mitani Y, Osakada K (1992) Flow stress and phase transformation analyses in the austenitic stainless steel under cold working (Part 1, phase transformation characteristics and constitutive formulation by energetic criterion). JSME Int $\mathrm{J}$ Series I 35(2):201-209

9. Tsuta T, Cortes JA (1993) Flow stress and phase transformation analyses in the austenitic stainless steel under cold working (Part 2 , incremental theory under multiaxial stress state by the finiteelement method). JSME Int J Series A 36(1):63-72

10. Olson GB, Cohen M (1975) Kinetics of strain-induced martensitic nucleation. Metall Trans A 6A:791-795

11. Hora P, Tong L, Reissner J (2003) Mathematical prediction of FLC using macroscopic instability criteria combined with micro structural crack propagation models. Proceedings of the Plasticity'03

12. Hora P, Tong L (2008) Theoretical prediction of the influence of curvature and thickness on the FLC by the enhanced modified maximum force criterion. Proceedings of the Numisheet'08, pp $205-210$ 
13. Hora P, Volk W, Roll K, Griesbach B, Kessler L, Hotz W (2008) Benchmark 1 - virtual forming limit curves. Proceedings of the Numisheet'08 - Part B

14. Hora P, Tong L (1994) Prediction methods for ductile sheet metal failure using FE-simulation. Proceedings of the IDDRG'94

15. Hora P, Tong L, Reissner J (1996) A prediction method for ductile sheet metal failure. Proceedings of the Numisheet'96

16. Krauer J, Hora P, Tong L, Berisha B (2007) Forming limit prediction of metastable materials with temperature and strain induced martensite transformation. Proceedings of the Numiform'07, pp 1263-1268
17. Krauer J, Hora P, Tong L (2008) Temperature dependent forming limit prediction for metastable stainless. Proceedings of the Numisheet'08, pp 235-240

18. Vogel H (1921) The temperature dependence law of the viscosity of fluids. Physikalische Zeitschrift 22:645-646

19. Grüebler R, Hora P (2009) Temperature and velocity dependent friction modelling for sheet metal forming. Int $\mathrm{J}$ Mater Form, Supplement, pp 251-254

20. Krauer J (2010) Erweiterte Werkstoffmodelle zur Beschreibung des thermischen Umformverhaltens metastabiler Stähle, PhDThesis ETH Nr. 19070, Fortschr.-Ber. VDI Reihe 2 Nr. 676, VDI Verlag 